\title{
MK2206 potentiates cisplatin- induced cytotoxicity and apoptosis through an interaction of inactivated Akt signaling pathway
}

\section{$\operatorname{AUTHOR(S):~}$}

Sun, Dingqi; Sawada, Atsuro; Nakashima, Masakazu; Kobayashi, Takashi; Ogawa, Osamu; Matsui, Yoshiyuki

\section{CITATION:}

Sun, Dingqi ... [et al]. MK2206 potentiates cisplatin-induced cytotoxicity and apoptosis through an interaction of inactivated Akt signaling pathway. Urologic oncology 2014, 33(3): 111.e17-111.e26

\section{ISSUE DATE:}

2014-12-09

URL:

http://hdl.handle.net/2433/198742

\section{RIGHT:}

(c) 2015 Elsevier Inc. Licensed under the Creative Commons Attribution-NonCommercial-NoDerivatives 4.0 International http://creativecommons.org/licenses/by-nc-nd/4.0/. NOTICE: this is the author's version of a work that was accepted for publication in <Urologic Oncology: Seminars and Original Investigations>. Changes resulting from the publishing process, such as peer review, editing, corrections, structural formatting, and other quality control mechanisms may not be reflected in this document. Changes may have been made to this work since it was submitted for publication. A definitive version was subsequently published in [Urologic Oncology: Seminars and Original Investigations, Volume 33, Issue 3, Pages 111.e17-111.e26] doi:10.1016/j.urolonc.2014.10.018; 許諾条件により本文ファイルは2015-12-09に公開， この論文は出版社版でありません。引用の際には出版社版をご確認ご利用ください。; This is not the published version. Please cite only the pub... 


\title{
MK2206 potentiates cisplatin-induced cytotoxicity and apoptosis through an interaction of inactivated Akt signaling pathway
}

Dingqi Sun ${ }^{\mathrm{a}, \mathrm{b}}$, Atsuro Sawada ${ }^{\mathrm{a}}$, Masakazu Nakashima ${ }^{\mathrm{a}}$, Takashi Kobayashi $^{\mathrm{a}}$, Osamu Ogawa ${ }^{\mathrm{a}}$, Yoshiyuki Matsui ${ }^{\mathrm{a}, *}$

${ }^{a}$ Department of Urology, Graduate School of Medicine, Kyoto University, Kyoto, Japan

b Department of Urology, Provincial Hospital Affiliated to Shandong University, Jinan, Shandong, People’s Republic of China

*Correspondence: Yoshiyuki Matsui, Department of Urology, Graduate School of Medicine, Kyoto University, 54 Shogoin Kawahara-cho, Sakyo-ku, Kyoto 606-8507, Japan.

Tel: 81-75-751-3337; Fax: 81-75-761-3740

E-mail: ym1108@kuhp.kyoto-u.ac.jp

\begin{abstract}
Objectives: To improve conventional chemotherapeutic efficacy, it is important to detect new molecular markers for chemosensitivity as well as possible accelerating cell killing mechanism. In this study, we investigated how MK2206, an allosteric Akt inhibitor, enhances the
\end{abstract}


cisplatin (CDDP)-induced cytotoxicity and apoptosis in urothelial cancer cells.

Materials and methods: We examined bladder cancer cell lines for the expression of phospho-Akt and its downstream targets by Western blot. The potential antitumor effects were analyzed by MTT assay in vitro and by subcutaneous xenograft models in vivo. The cell invasion was examined by transwell invasion assay, and the activities of Akt signaling pathway and expression of apoptosis-related proteins were measured by Western blot.

Results: The expression of phospho-Akt and its downstream targets was increased in invasive bladder cancer cell lines vs in noninvasive bladder cancer cell lines. MK2206 (500 nM) inhibited cell invasion in UMUC3 cell line and significantly increased the susceptibility of bladder cancer cell lines to CDDP. When used in combination with CDDP, MK2206 (500 nM) enhanced CDDP-induced cytotoxicity and apoptosis, with suppressed expression of p-Akt and its downstream targets. In vivo MK2206 combined with CDDP effectively suppressed tumor growth in subcutaneous xenograft models.

Conclusions: These results suggest that concomitant use of MK2206 could promote the CDDP-induced cytotoxicity and apoptosis in urothelial cancer cell lines through the inhibited expression of Akt pathway. This combined treatment may provide a new therapeutic option to enhance 
chemosensitivity in bladder cancer.

Key words: urothelial cancer, cisplatin, Akt pathway, MK2206, invasion 


\section{Introduction}

Urothelial cancers are common malignancies and considerable causes of morbidity and mortality. Muscle-invasive bladder urothelial cancers are difficult to control by less-invasive transurethral resection and often require radical cystectomy [1]. Even after complete removal, the patient prognosis is poor because of frequent metastatic recurrence. Cisplatin (CDDP)-based chemotherapy has been adopted for these advanced or recurrent urothelial cancers, although the use of chemotherapy is associated with significant toxicity and provides long-term survival in only $15-20 \%$ of patients due to innate or acquired resistance to chemotherapy. To improve chemotherapeutic efficacy and explore the molecular mechanisms, it is important to detect novel molecular markers for chemosensitivity and identify possible target-associated cell-killing mechanisms in urothelial cancer cells.

Akt is a serine-threonine kinase activated by growth factors or survival factors to regulate cell growth, survival, proliferation and metabolism [2-4]. The Phosphatidylinositol-3 kinase (PI3K)/Akt pathway plays a key role in survival when cancer cells are exposed to different kinds of apoptotic stimuli, such as the withdrawal of extracellular signaling factors, oxidative and osmotic stress, irradiation, matrix adhesion, ischemic shock and chemotherapeutic drugs [5-8]. Recent evidence indicates that Akt is frequently constitutively activated in many types of human cancer, and 
activated Akt signaling is a significant contributor to tumor progression and poor prognosis, including bladder cancer [9-11]. Moreover, Akt overexpression is often associated with resistance to chemotherapy or radiotherapy [12,13]. Dominant-negative mutants of Akt enhance the cytotoxicity of chemotherapeutic agents, suggesting an important role of Akt in drug resistance [14]. Some studies have shown that Akt activation seems to be related to CDDP resistance of ovarian cancer cells and lung cancer cells $[15,16]$. Thus, chemotherapeutic agents that could be sensitized by Akt inhibition is highly desirable to guide the clinical application of Akt inhibitors.

MK2206 is a highly potent and selective allosteric Akt inhibitor that is under development for the treatment of solid tumors. Previous reports have demonstrated that MK2206 has antitumor activity alone and enhanced antitumor efficacy in combination with chemotherapeutic agents in solid tumors [17-21]. In the present study, we demonstrated that the effectiveness of MK2206 to enhance CDDP-induced cytotoxicity and apoptosis, through the inhibition of phospho-Akt expression and its downstream targets. This study may provide useful information to develop a potential new therapeutic approach for bladder cancer by targeting the Akt pathway to increase CDDP sensitivity.

\section{Materials and methods}




\subsection{Antibodies and reagents}

Antibodies were obtained as follows: anti-Akt, phospho-Akt (ser473), phospho-Akt (Thr308), phospho-4EBP1, phospho-mTOR, phospho-S6RP, phospho-70S6K, phospho-GSK3 $\beta$, anti-mTOR, bax, survivin (71G4B7), cleaved caspase-3, Ki-67, Snail, Slug and TCF8/ZEB1 from Cell Signaling Technology (Bevery, MA). Anti-caspase-8, anti-caspase-9 from BD Pharmingen (San Diego, CA). MK2206 was obtained from Active Biochem (Maplewood, NJ) and CDDP was from WAKO (Osaka, Japan).

\subsection{Cell culture}

Six bladder cancer cell lines (RT112, RT4, 253J, J82, T24, UMUC3) were maintained in RPMI1640 medium supplemented with $10 \%$ fetal bovine serum and 1\% penicillin/streptomycin. Cells were incubated at $37^{\circ} \mathrm{C}$ in a humidified atmosphere containing $5 \% \mathrm{CO}_{2}$.

\subsection{MTT assay}

Cell viability was assessed by MTT assay. Briefly, $1 \times 10^{4}$ cancer cells with $100 \mu$ l suspension were grown in each well of 96-well plates. After $24 \mathrm{~h}$ of incubation, cells were treated with or without different concentrations of drugs for another 24h. Then, $20 \mu \mathrm{l}$ MTT working solution (5 mg/ml; Sigma) was added to each culture well and incubated for $4 \mathrm{~h}$. The absorbance $(A)$ of each well was measured by a microculture plate reader (Immunoreader, Japan Intermed Co., Ltd., Tokyo, Japan) at $540 \mathrm{~nm}$. The percentage of cell viability $=($ A of experimental wells $/$ A of 
control wells $) \times 100$. These experiments were performed at least three times independently.

\subsection{Drug treatment and preparation of cellular extracts}

For the dose-response and the time-course studies, cells were grown to $70-80 \%$ confluency in $100 \mathrm{~mm}$ dishes for $48 \mathrm{~h}$. Then cells were treated with CDDP at the corresponding concentrations of IC30. For analysis of Akt pathway, cells were treated with CDDP at the concentration corresponding to IC30 with or without treatment of 500 nM MK2206. After treatment, cells were washed with phosphate-buffered saline (PBS) and lysed in an appropriate volume of ice-cold cell lysis buffer (20 mM Tris, PH 7.4, 150 mM NaCl, 1 mM EDTA, 1mM EGTA, 1\% Triton, 2.5 mM sodium pyrophosphate, $1 \mathrm{mM}$ beta-glycerophosphate, $1 \mathrm{mM} \mathrm{Na}_{3} \mathrm{VO}_{4}$, $1 \mu \mathrm{g} / \mathrm{ml}$ leupeptin) supplemented with $1 \mathrm{mM}$ phenyl-methylsulfonyl fluoride. Cellular lysates were clarified by centrifugation at $15000 \times g$ for $20 \mathrm{~min}$, and the protein concentrations of the lysates were determined by a detergent-compatible protein assay kit (Bio-Rad, Hercules, CA). Portions of the same cellular extracts were used for Western blot analysis.

\subsection{Western blot analysis}

Thirty to fifty micrograms of protein lysates were separated by SDS-PAGE on a 10-15\% Tris-HCL minigel, and transferred onto a PVDF membrane following standard methods. After blocking, membranes were probed with appropriate dilutions of primary antibodies overnight, 
followed by incubation with horseradish peroxidase-conjugated secondary antibodies 1h. Proteins were visualized by the chemiluminescent detection system.

\subsection{Transwell invasion assay}

For transwell invasion assays, cells were suspended in serum-free RPMI 1640. The cell suspensions UMUC3 $\left(5 \times 10^{4}\right)$ were then added to the $8.0 \mu \mathrm{m}$ pore polyethylene terephthalate filter insert of a 24-well transwell cell culture chamber (BD Falcon, Franklin Lakes, NJ, USA) and were incubated for $24 \mathrm{~h}$ with medium containing $10 \%$ FBS in the bottom of the chamber. Residual cells on the upper side of chambers were removed by scraping with cotton swabs and the cells that attached to the lower side of the membrane were fixed with $70 \%$ ethanol and stained with hematoxylin. The number of invaded cells was counted in 3 randomly selected fields $(\times 200)$ under microscope. Each experiment was triplicated and performed three times independently.

\subsection{Mouse xenograft model}

To produce a subcutaneous xenograft model, $5 \times 10^{6}$ RT112 cells in 100 $\mu \mathrm{l}$ phosphate buffered saline were inoculated subcutaneously into each flank of pathogen-free 5-week-old female BALB/cAJcl-nu/nu mice (Nihon Clea, Japan). After growing for 7 days, mice with tumor xenograft were divided into four groups (5 mice each group) and treated for 2 weeks as follows: (a) vehicle alone (DMSO); (b) CDDP at $6 \mathrm{mg} / \mathrm{kg}$ 
weekly; (c) MK2206 at $50 \mathrm{mg} / \mathrm{kg}$ weekly; (d) combination of (b) and (c). We administered CDDP or MK2206 by intraperitoneal injection. The doses and injection regimens for these drugs were based on reports published previously [19,22]. Mice body weight and tumor size were measured every other day. Tumor volume was calculated using the equation, volume= $=$ width $^{2} \times$ length/2. All mice were sacrificed on day 15 after initial treatment. Tumors were excised and formalin fixed for Ki-67 immunostaining. Approval for these studies was obtained from the Animal Research Committee of Graduate School of Medicine, Kyoto University.

\subsection{Statistical analysis}

Statistical data was analyzed using Statistical Package for Social Sciences (SPSS, version 17.0) software. All data used were representative of at least three independent experiments. Quantitative data were expressed as mean \pm S.D. Comparisons were carried out by the Mann-Whitney $U$ test and Kruskal-Wallis test. $P$ values $<0.05$ were considered statistically significant.

\section{Results}

\subsection{Expression status of Akt signaling pathway in urothelial cancer cell lines}

The expression status of phospho-Akt and its downstream targets were 
examined using six urothelial cancer cell lines (RT112, RT4, 253J, J82, T24, UMUC3). Invasive cell lines had overexpression of p-Akt (Ser473), p-Akt (Thr308) and downstream targets, including p-4EBP1, p-GSK3 $\beta$, p-mTOR, p-70S6K and p-S6RP (Fig. 1). There were no or weak expressions of Akt signaling in noninvasive cell lines, RT112 and RT4. However, RT112 had the activation of p-70S6K and p-S6RP.

\subsection{The impact of MK2206 on phospho-Akt expression, cell proliferation, cell invasion in urothelial cancer cell lines}

To analyze the effects of MK2206 on phospho-Akt expression, the four invasive cell lines were treated with increasing doses of MK2206 for 24 hours. Dose-dependent decreases in the p-Akt (Ser473) expression were shown in these cell lines (Fig. 2A). The effects of MK2206 on cell proliferation were investigated by MTT assay, corresponding to the same concentrations of WB (Fig. 2B). The cell viability rates after 500nM MK2206 exposure were $84.24 \pm 2.29,84.34 \pm 1.64,82.52 \pm 2.31,80.88 \pm 1.98$, $81.92 \pm 2.12 \%$ in RT112, 253J, UMUC3, T24 and J82, respectively. In this study, we used the concentration (500 nM) at which MK2206 alone successfully suppressed p-Akt, but suppressed cell proliferation only modestly and did not induce apoptosis (Fig. 2B, Fig 4B-C).

In order to determine whether MK2206 had any effect on cell invasion, we performed Matrigel invasion chamber assay. UMUC3 was treated with control (DMSO) or MK2206 (500 nM) and incubated 24h before the 
invasion assay was taken. Invasion capability of UMUC3 treated with MK2206 was repressed significantly compared with control group (Fig. 2C, D). The invasion assay result was influenced by decreased cell proliferation because cell proliferation was suppressed about $20 \%$ by MK2206 at 500nM which could inhibit cell invasion rate around 50\% in UMUC3 cells (Fig. 2B, D). If normalized, the decrease in cell invasion would be roughly $30 \%$. To clarify the functional relevance of molecules which were associated with tumor invasion or migration, the expression of Snail, Slug and ZEB1 were examined using Western Blot after MK2206 treatment. Repression of Snail, Slug and ZEB1 were shown when cells were treated with MK2206 for 24h (Fig. 2E). Meanwhile, Akt phosphorylation expression was also decreased when exposed to MK2206 (500 nM) for 24h in UMUC3 (Fig. 2A). We also tried invasion assay in T24, and the observation that MK2206 effect on invasion on the T24 invasive cell line is similar with UMUC3. These data may indicate that the decreased expression of Akt phosphorylation was associated with tumor invasion inhibition through suppression of Snail, Slug and ZEB1.

\subsection{Sensitivity to CDDP in urothelial cancer cell lines and MK2206 enhanced CDDP-induced cytotoxicity}

The sensitivity to CDDP differed among cells: IC50 monitored by MTT assay were $62.6 \pm 2.4, \quad 106.7 \pm 7.2, \quad 122.1 \pm 12.7, \quad 355.4 \pm 5.6$, 404.3 \pm 14.0 and $695.2 \pm 123.1 \mu \mathrm{M}$ in RT4, RT112, 253J, UMUC3, J82 and 
T24, respectively (Fig. 3A). Combination with 500 nM MK2206 significantly enhanced sensitivity to CDDP dose-dependently. Significant differences in growth rates were observed and statistical differences between CDDP and CDDP+MK2206 were $p=0.004, p=0.01, p=0.028$, $p=0.028$ in RT112, 253J, UMUC3 and T24, respectively (Fig. 3B).

\subsection{Involvement of suppression of Akt pathway in MK2206-mediated enhancement of CDDP-induced apoptosis}

To investigate the molecular mechanisms underlying the effects of MK2206 in CDDP-induced apoptosis, the p-Akt, p-mTOR, p-4EBP1, survivin, Bax, and caspases were examined after MK2206, CDDP and CDDP+MK2206 treatment in a time-dependent manner in T24 (Fig. 4A.1-2). Western blot analysis showed that MK2206 (500nM) alone could inhibit the p-Akt expression, but could not induce cleaved forms of apoptosis targets (caspases-8/caspase-9/caspase-3) in the time course (Fig. 4A.1). Concomitant use of CDDP (300 $\mu \mathrm{M})$ and MK2206 (500 nM) did not change the expression of Akt, but it suppressed phosphorylation of Akt, 4EBP1 from 3h and phosphorylation of mTOR from 9h. The activation of caspase-8/caspase-9/caspase-3, as shown by an increase in their cleaved products, occurred from 9h after CDDP plus MK2206 exposure, but CDDP itself caused slight cleaved forms of caspase-8/caspase-3 only in $12 \mathrm{~h}$, with no significant change in phosphorylation of Akt, 4EBP1, and mTOR. The downregulation of 
survivin, as an anti-apoptotic protein, was observed in $12 \mathrm{~h}$ after CDDP combined with MK2206 treatment (Fig. 4A.2).

To further assess the effects of Akt pathway on the CDDP-induced apoptosis, Western blot was performed using T24 and RT112 cells, which were incubated $12 \mathrm{~h}$ with indicated reagents (Fig. 4B, C). Single treatment with CDDP (300 $\mu \mathrm{M})$ slightly induced cleaved forms of caspase-8 / caspase-3, and did not increase the expression of p-Akt, Akt, p-4EBP1 and p-mTOR significantly in T24 (Fig. 4B). On the other hand, the cleaved products of caspase-8/caspase-9/caspase-3 were observed in RT112 with the single treatment of CDDP. Interestingly, compared with T24, in which there was no obvious change in the expression of Akt signaling through CDDP exposure, significant increase in its expression after CDDP (50 $\mu \mathrm{M})$ exposure was identified in RT112 (Fig. 4C). MK2206 and CDDP induced significant suppression of p-Akt, p-4EBP1, p-mTOR, survivin and activated caspases in both cell lines, in contrast to MK2206 or CDDP single treatment. These findings suggested that suppression of Akt pathway played an important role in the enhancement of CDDP-induced apoptosis.

\subsection{MK2206 effectively enhanced CDDP-induced cytotoxicity in mouse in vivo model}

For the clinical use of MK2206 for urothelial carcinoma, we examined the effects of MK2206 alone or in combination with CDDP to the in vivo 
growth of RT112 cells, using a subcutaneous xenograft model. CDDP and MK2206 were given weekly, respectively. Significant body weight change in the mice could not be observed and the treatment was well tolerated. In our conditions, CDDP or MK2206 partially delayed tumor growth and the combination therapy suppressed tumor growth (Fig. 5A). The tendency of tumor growth inhibition was observed among groups, but there were no statistical differences among groups $(P>0.05)$. Ki-67 immunostaining of tumors demonstrated that combination treatment of MK2206 and CDDP could reduce tumor cells proliferation, compared with CDDP treatment alone. These results suggested that MK2206 could enhance CDDP-induced cytotocixity in vivo as well as in vitro.

\section{Discussion}

In the present study, we demonstrated that MK2206, one kind of Akt inhibitor, specifically enhanced the CDDP-induced cytotoxicity and apoptosis with the suppression of Akt pathway in urothelial cancer cell lines. The Akt pathway has been emphasized for the oncogenesis of many kinds of malignancy. We showed that MK2206 sensitized these cancer cells to CDDP via the inhibition of phosphorylation of Akt and its downstream molecules in Akt pathway. These results indicated that Akt pathway is a novel candidate to influence chemosensitivity to CDDP in urothelial cancers. 
Overactivation of Akt can influence many downstream effectors and mediate multiple pathways that favour tumourigenesis and as such it is one of the most frequently hyperactivated protein kinases in human cancer [23]. Akt, as one of the important target in phosphatidylinositol-3 kinase (PI3K)/Akt signaling pathway, has three isoforms: Akt1, Akt2 and Akt3 [2,24]. The Akt pathway can be activated by numerous growth factors, mitogens, hormones and nutrients. Meanwhile, it can also be activated by the disruption of negative feedback mechanisms. The phosphatase and tensin homologue (PTEN), as a tumor suppressor, negatively regulates the Akt pathway by hydrolysing phosphatidylinositol triphosphate (PIP3) to phosphatidylinositol biphosphate (PIP2). Loss of PTEN strongly correlates with the activation of Akt in tumour cell lines, and recent studies have shown that reduced PTEN expression is common in UC $[25,26]$. The activation of Akt signaling pathway correlates with tumor progression and reduced survival in urothelial cancer. The high expression of p-Akt corresponded significantly with high-grade, advanced-stage and a higher risk of mortality in patients with urothelial cancer [10].

MK2206, a highly selective allosteric inhibitor of Akt, is being tested in both preclinical settings and clinical trials as an anticancer agent. MK2206 by itself causes cell proliferation inhibition of cell lines, including non-small-cell lung cancer lines, hepatocellular cancer lines, 
breast cancer lines, nasopharyngeal carcinoma cell lines and so on [17-19,27]. MK2206 also could synergistically enhance antitumor efficacy with some chemotherapeutic drugs. Meanwhile, cell invasion can be inhibited when treated with MK2206 in glioma cell lines, and cell invasion suppression coincided with decreased Akt phosphorylation [28]. In our study, MK2206 (500 nM) alone suppressed Akt phosphorylation effectively using the concentration which could inhibit cell proliferation modestly in urothelial cancer cell lines. Further, it has been shown that cell invasion rate was suppressed significantly by MK2206 (500 nM), with the inhibition of Snail and ZEB1 which were transcription factors related with epithelial to mesenchymal transition (EMT). In addition, our study showed that the result of invasion assay was influenced by decreased cell proliferation. Cell proliferation was suppressed about 20\% by MK2206 at 500nM, which was the same dose in invasion assay. So if normalized, the decrease in cell invasion rate would be roughly $30 \%$. It has been reported that Snail and ZEB1 expression were associated with invasion, metastasis and decreased chemosensitivity in some tumors, and inhibition of those targets increased the chemosensitivity [29-31]. Our results may indicate that suppressed Akt phosphorylation played a role in the inhibition of cell invasion and repression of Snail and ZEB1.

To investigate the possible role of Akt in the CDDP-induced cytotocixitiy, we examined the impact of cell proliferation in urothelial 
cancer cell lines. Invasive cell lines were increasingly resistant to CDDP than noninvasive cell lines, and combination use of CDDP and MK2206 clearly inhibited cell proliferation in comparison with single use of CDDP. Previous data has suggested that Akt regulated CDDP sensitivity in human lung cancer and ovarian cancer $[15,16]$. Therefore, Akt inhibition is suspected to have a mechanism to promote CDDP susceptibility. We found the contribution of Akt pathway inhibition to apoptosis using MK2206, by showing the enhancement of CDDP-induced apoptosis in CDDP plus MK2206. Conformational change of survivin by MK2206 has been reported to cause survivin suppression [19]. Our result showed that the change of survivin protein may mediate apoptosis through blockade of Akt pathway. These findings suggest that MK2206 might inhibit the activation of Akt pathway, leading to acceleration of CDDP-induced apoptosis. Here, we showed that the combination therapy may be effective to overcome the pre-existing resistance to chemotherapeutic drug of bladder cancer, that is, promotion of chemosensitivity. But another important subject of chemotherapy against bladder cancer is chemoresistance acquired during the chemotherapy, that is, treatment refractory. To examine the effectiveness of this combination therapy against chemoresistance, we need further experiments using CDDP-resistant cell lines in the future. If this treatment is also effective against chemoresistant situation, indication of this combination therapy 
would be further expanded.

In this study, we also demonstrated that 4EBP1 and mTOR seem to act as the downstream targets of Akt pathway to promote apoptosis. Generally, p-4EBP1 and p-mTOR have a close relation to protein synthesis, and the activation of p-4EBP1 and p-mTOR has been reported to increase in the regulation of tumor growth [32]. Previous findings have suggested that cell cycle arrest, apoptosis, and autophagy were induced in T-ALL cells through inhibiting Akt/mTOR/4EBP1 [33]. Piperlongumine induce caspase-dependent apoptosis in human breast cancer cells via the inhibition of p-Akt, p-70S6K, p-4EBP1 [34]. From our data, considerable apoptosis was detected in combination use of CDDP and MK2206, depending on the suppression of Akt signaling pathway including reduction of p-4EBP1 and p-mTOR. Interestingly, our results showed that CDDP-induced Akt activation was observed significantly in RT112, not in T24. Whereas combined treatment of CDDP and MK2206 inhibited CDDP-induced activation of Akt, 4EBP1 and mTOR in both of cell lines.

To assess the clinical usefulness and safety, we used a subcutaneous xenograft tumor model. In this model, MK2206 was administered by intraperitoneally at $50 \mathrm{mg} / \mathrm{kg}$ once per week. This dose was lower than those reported previously [19], which used the dose of $100 \mathrm{mg} / \mathrm{kg}$ once per week, but this low concentration could still enhance cancer-specific 
CDDP-induced cytotoxicity and significant tendency of tumor growth inhibition was found in combination therapy group. However, statistical differences could not be observed among groups. When we consider clinical application of MK2206 at a low concentration with chemotherapeutic agents, a combination with CDDP, which is one of the most frequently used agents for urothelial cancer, is a very attractive choice.

\section{Conclusions}

In the current study, we demonstrated that MK2206 could promote CDDP-induced cytotoxicity and apoptosis in urothelial cancer cells by the suppression of Akt activation and its downstream targets. Akt target therapy using MK2206 will develop as a promising strategy applied to enhance chemosensitivity to CDDP in urothelial cancers. 
[1] Nishiyama H, Habuchi T, Watanabe J, et al. Clinical outcome of a large-scale multi-institutional retrospective study for locally advanced bladder cancer: a survey including 1131 patients treated during 1990-2000 in Japan. Eur Urol 2004; 45: 176-81.

[2] Bellacosa A, Testa JR, Staal SP, et al. A retroviral oncogene, akt, encoding a serine-threonine kinase containing an SH2-like region. Science 1991; 254: 274-7.

[3] Burgering BM, Coffer PJ. Protein kinase B (c-Akt) in phosphatidylinositol-3-OH kinase signal transduction. Nature 1995; 376: 599-602.

[4] Datta SR, Brunet A, Greenberg ME. Cellular survival: a play in three Akts. Genes Dev 1999;13:2905-27.

[5] Nogueira V, Park Y, Chen CC, et al. Akt determines replicative senescence and oxidative or oncogenic premature senescence and sensitizes cells to oxidative apoptosis. Cancer Cell 2008; 14: 458-70.

[6] Pastukh V, Ricci C, Solodushko V, et al. Contribution of the PI3-kinase/Akt survival pathway toward osmotic preconditioning. Mol Cell Biochem 2005; 269: 59-67.

[7] Mullonkal CJ, Toledo-Pereyra LH. Akt in ischemia and reperfusion. J Invest Surg 2007; 20: 195-203.

[8] West KA, Castillo SS, Dennis PA. Activation of the PI3K/Akt pathway and chemotherapeutic resistance. Drug Resist Updat 2002; 5: 
234-48.

[9] Nicholson KM, Anderson NG. The protein kinase B/Akt signaling pathway in human malignancy. Cell Signal 2002; 14: 381-95.

[10] Sun CH, Chang YH, Pan CC. Activation of the PI3K/Akt/mTOR pathway correlates with tumour progression and reduced survival in patients with urothelial carcinoma of the urinary bladder. Histopathology 2011; 58: 1054-63.

[11] Knowles MA, Platt FM, Ross RL, et al. Phosphatidylinositol 3-kinase (PI3K) pathway activation in bladder cancer. Cancer Metastasis Rev 2009; 28: 305-16.

[12] Winograd-Katz SE, Levitzki A. Cisplatin induces PKB/Akt activation and p38 MAPK phosphorylation of the EGF receptor. Oncogene 2006; 25: 7381-90.

[13] Bellacosa A, Kumar CC, Di Cristofano A, et al. Activation of AKT kinases in cancer: implications for therapeutic targeting. Adv Cancer Res 2005; 94: 29-86.

[14] Brognard J, Clark AS, Ni Y, et al. Akt/protein kinase B is constitutively active in non-small cell lung cancer cells and promotes cellular survival and resistance to chemotherapy and radiation. Cancer Res 2001; 61: 3986-97.

[15] Yang X, Fraser M, Moll UM, et al. Akt-mediated cisplatin resistance in ovarian cancer: modulation of p53 action on caspase-dependent 
mitochondrial death pathway. Cancer Res 2006; 66: 3126-36.

[16] Liu LZ, Zhou XD, Qian G, et al. AKT1 amplification regulates cisplatin resistance in human lung cancer cells through the mammalian target of rapamycin/p70S6K1 pathway. Cancer Res 2007; 67: 6325-32.

[17] Sangai T, Akcakanat A, Chen H, et al. Biomarkers of response to Akt inhibitor MK2206 in breast cancer. Clin Cancer Res 2012; 18: 5816-28.

[18] Hirai H, Sootome H, Nakatsuru Y, et al. MK-2206, an allosteric Akt inhibitor, enhances antitumor efficacy by standard chemotherapeutic agents or molecular targeted drugs in vitro and in vivo. Mol Cancer Ther 2010; 9: 1956-67.

[19] Ou DL, Lee BS, Lin LI, et al. Vertical blockade of the IGFR-PI3K/Akt/mTOR pathway for the treatment of hepatocellular carcinoma: the role of survivin. Mol Cancer 2014; $13: 2$.

[20] Grabomski N, Ewald F, Hofmann BT, et al. Combined targeting of Akt and mTOR synergistically inhibits proliferation of hepatocellular carcinoma cells. Mol Cancer 2012; 11:85.

[21] Cheng Y, Zhang Y, Zhang L, et al. MK-2206, a novel allosteric inhibitor of Akt, synergizes with gefitinib against malignant glioma via modulating both autophagy and apoptosis. Mol Cancer Ther 2012; 11: 154-64.

[22] Matsui Y, Watanabe J, Ikegawa $M$, et al. Cancer-specific enhancement of cisplatin-induced cytotoxicity with triptolide through an 
interaction of inactivated glycogen synthase kinase-3beta with p53. Oncogene 2008; 27: 4603-14.

[23] Altomare DA, Testa JR. Perturbations of the AKT signaling pathway in human cancer. Oncogene 2005; 24: 7455-64.

[24] Jones PF, Jakubowicz T, Pitossi FJ, et al. Molecular cloning and identification of a serine/threonine protein kinase of the second-messenger subfamily. Proc Natl Acad Sci USA 1991; 88: 4171-5. [25] Dahia PL, Aguiar RC, Alberta J, et al. PTEN is inversely correlated with the cell survival factor $\mathrm{Akt} / \mathrm{PKB}$ and is inactivated via multiple mechanismsin haematological malignancies. Hum Mol Genet 1999; 8: 185-93.

[26] Tsuruta H, Kishimoto H, Sasaki T, et al. Hyperplasia and carcinomas in Pten-deficient mice and reduced PTEN Protein in human bladder cancer patients. Cancer Research 2006; 66: 8389-96.

[27] Ma BB, Liu VW, Hui CW, et al. Preclinical evaluation of the Akt inhibitor MK2206 in nasopharyngeal carcinoma cell lines. Invest New Drugs 2013; 31: 567-75.

[28] Jin R, Nakada M, Teng L, et al. Combination therapy using Notch and Akt inhibitors is effective for suppressing invasion but not proliferation in glioma cells. Neurosci Lett 2013;534:316-21.

[29] Yin T, Wang C, Liu T, et al. Expression of snail in pancreatic cancer promotes metastasis and chemoresistance. J Surg Res 2007; 141: 
196-203.

[30] Siebzehnrubi FA, Silver DJ, Tuqertimur B, et al. The ZEB1 pathway links glioblastoma initiation, invasion and chemoresistance. EMBO Mol Med 2013; 5: 1196-212.

[31] Ren J, Chen Y, Song H, et al. Inhibition of ZEB1 reverses EMT and chmoresistance in doxetaxel-resistant human lung adenocarcinoma cell line. J Cell Biochem 2013; 114: 1395-403.

[32] Engelman JA, Luo J, Cantley LC. The evolution of phosphatidylinositol 3-kinases as regulators of growth and metabolism. Nat Rev Genet 2006; 7: 606-19.

[33] Ge J, Liu Y, Li Q, et al. Resveratrol induces apoptosis and autophagy in T-cell acute lymphoblastic leukemia cells by inhibiting Akt/mTOR and activating p38-MAPK. Biomed Environ Sci 2013; 26: 902-11.

[34] Shrivastava S, kulkarni P, Thummuri D, et al. Piperlongumine, an alkaloid causes inhibition of PI3K/Akt/mTOR signaling axis to induce caspase-dependent apoptosis in human triple-negative breast cancer cells. Apoptosis 2014; 19: 1148-64. 


\section{Figure legends}

Figure 1 Expression status of the Akt signaling pathway in urothelial cancer cell lines. Western blot shows the expression of Akt and its downstream targets in noninvasive and invasive urothelial cancer cell lines.

Figure 2 The effect of MK2206 treatment on phospho-Akt expression, cell proliferation, and cell invasion in urothelial cancer cell lines. A, cell lines were exposed to MK2206 at indicated dose for 24h, and the expression of p-Akt was examined with Western blot. B, cell viability curves after treatment with MK2206 as in A. Mean values from at least three independent experiments are shown; bars represent S.D. C-D, invasive capability of UMUC3 was evaluated by transwell invasion assay. The cell suspension ( $5 \times 10^{4}$ cells) and reagents (DMSO or MK2206) were added to the insert of a transwell cell culture chamber, incubated for $24 \mathrm{~h}$ with medium containing $10 \%$ FBS in the bottom of the chamber. The cells that attached to the lower side of the membrane were fixed with $70 \%$ ethanol and stained with hematoxylin. Each experiment was triplicate and the average number of cells in five microscopic fields $(\times 200)$ was defined as the number of invasive cells. Representative microscopic image (C) and quantitated cell numbers (mean \pm S.D.) of three independent experiments (D) were shown. E, UMUC3 cells were treated with control 
(DMSO) or MK2206 (500 nM) for 24h and abundance of indicated proteins were examined using Western blot.

Figure 3 Effect of combinatorial treatment with MK2206 and CDDP in urothelial cancer cell lines. A, cell viability was evaluated 24h after CDDP treatment at indicated concentrations using MTT assay among six urothelial cancer cell lines. B, MTT assay showing effect of CDDP treatment with or without MK2206 (500 nM) in indicated urothelial cell lines. Average values from at least three independent experiments are shown; bars represent S.D.

Figure 4 Influence of combined MK2206 treatment on CDDP-induced apoptosis in urothelial cancer cell lines. A.1, cells were exposed with MK2206 (500nM) alone for the indicated times. A.2, cells were treated with CDDP at the concentration corresponding to IC30 (300 $\mu \mathrm{M})$ with or without treatment of $500 \mathrm{nM}$ MK2206 for the indicated times and the abundance of indicated protein was examined using Western blot. '0h' refers to the time for addition of reagents. B-C, cells were harvested after treatment with or without CDDP at indicated doses corresponding IC30 for each cell line in the presence or absence of $500 \mathrm{nM} \mathrm{MK2206} \mathrm{for} \mathrm{12h.}$

Figure 5 Effect of combinatorial treatment with CDDP and MK2206 on 
the growth of RT112 subcutaneous xenograft tumor in vivo. A, the change of subcutaneous RT112 tumor volume measured using the Vernier Caliper. After tumors reached indicated volume, tumor-bearing mice were treated with indicated drugs as shown in the figure and described in 'Materials and methods', and the effect of indicated drugs on tumor growth was measured by the Vernier Caliper. B, histological examination of the effect of CDDP and MK2206 on RT112 tumor in vivo. At day 15, the mice were killed, and the tumors were dissected. Expression of Ki-67 was assessed by immunohistochemistry. Percentage of Ki-67 positive cells in each treatment group were compared (*, $P<0.05$ vs control; **, $P<0.05$, CDDP+MK2206 vs CDDP; CDDP+MK2206 vs MK2206). 
Fig-1

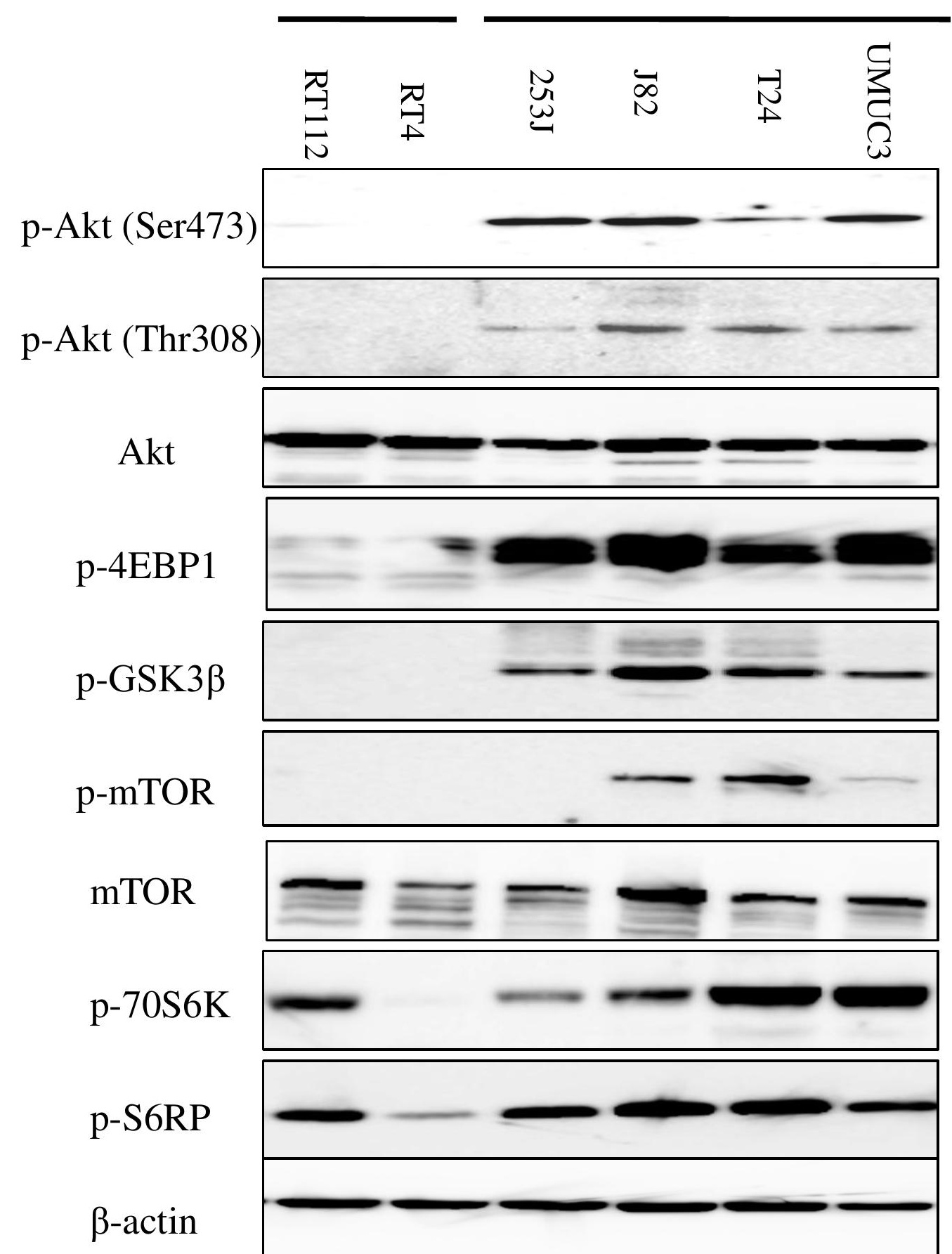


Fig-2A

MK2206

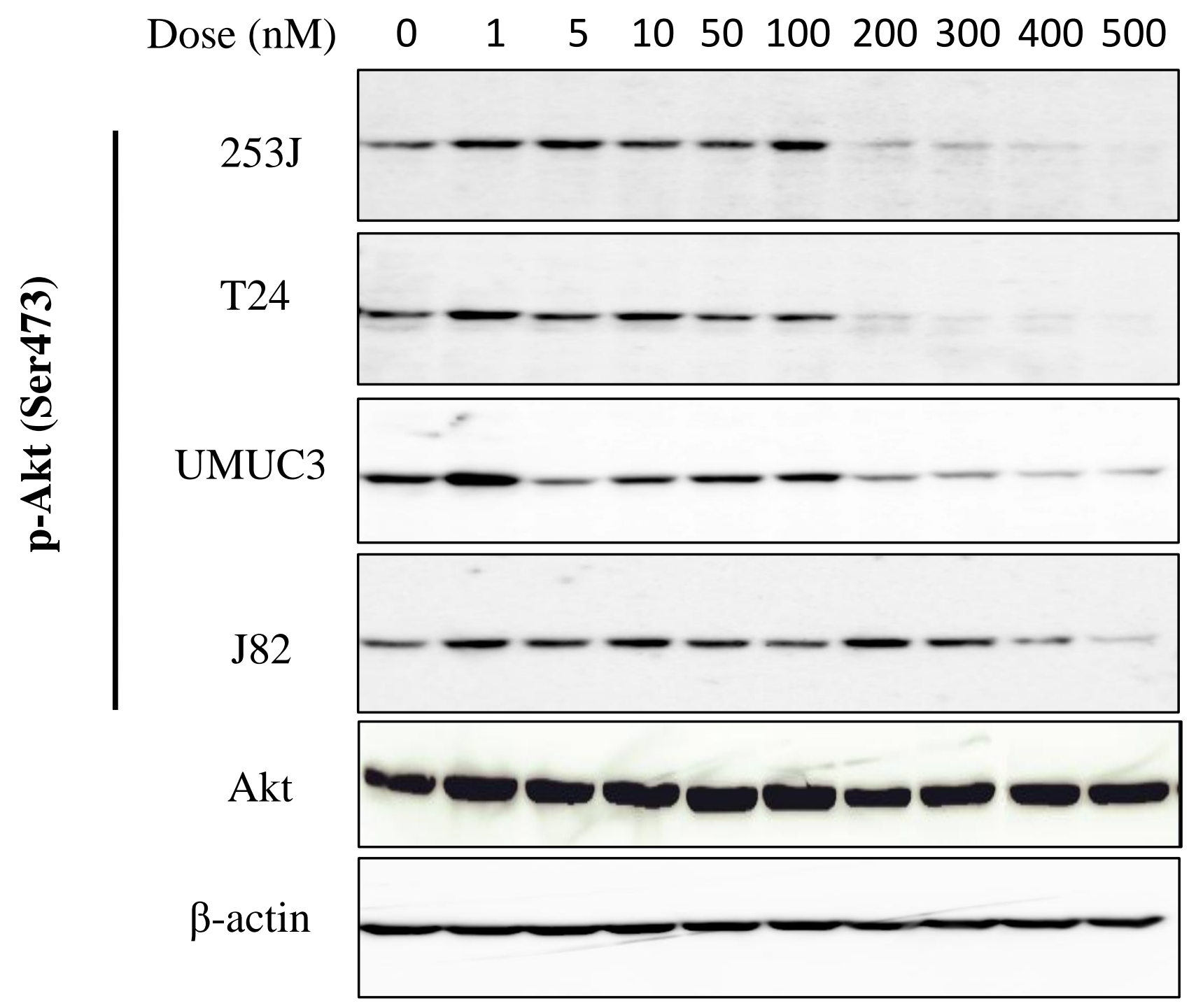


Fig-2B

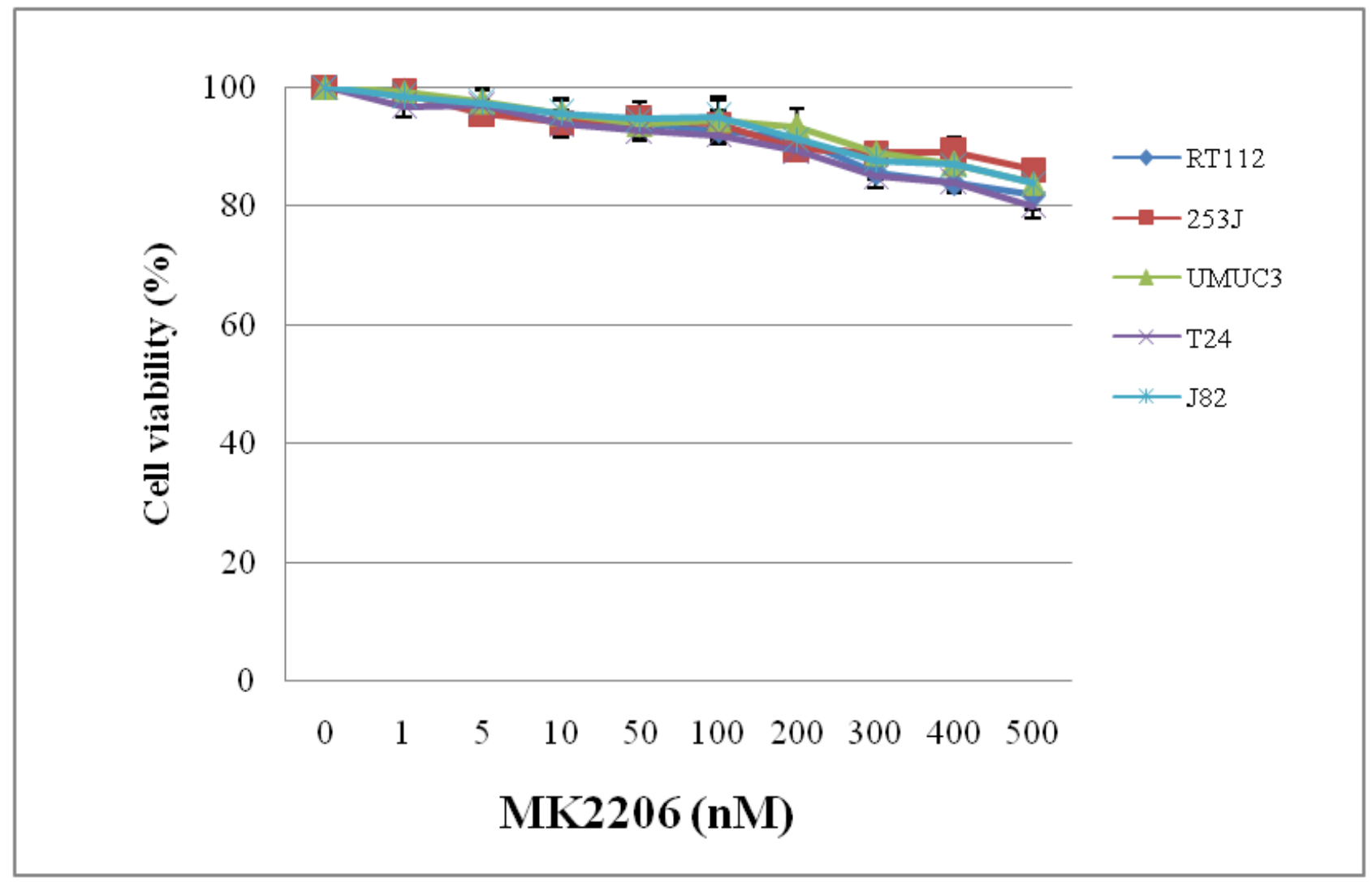


Fig-2C
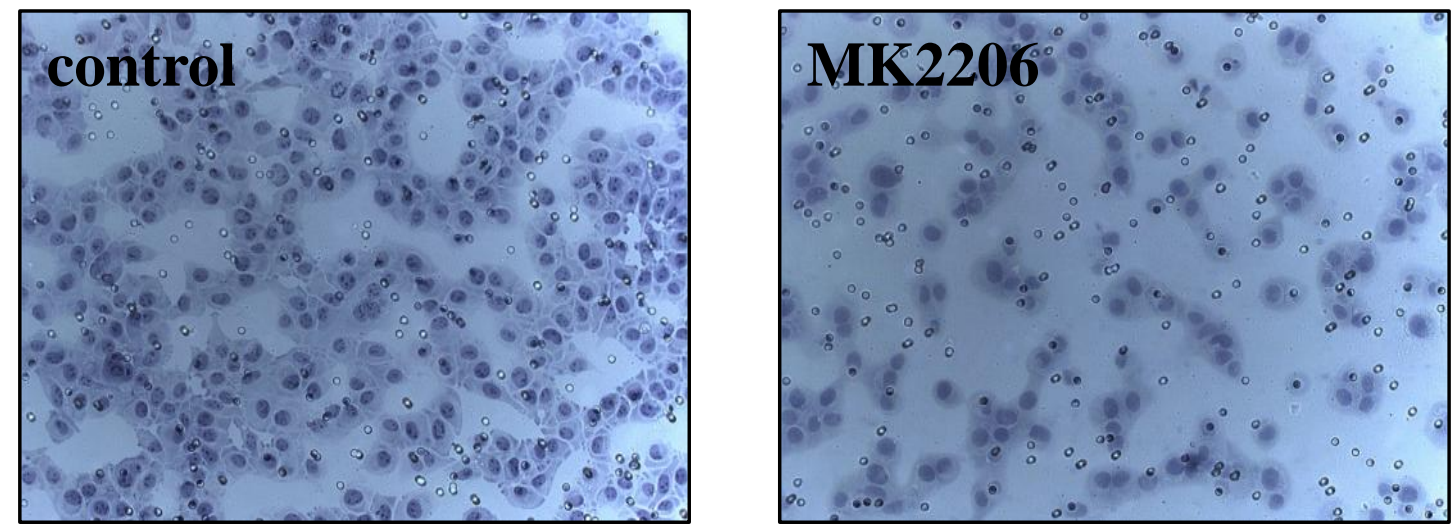

Fig-2D

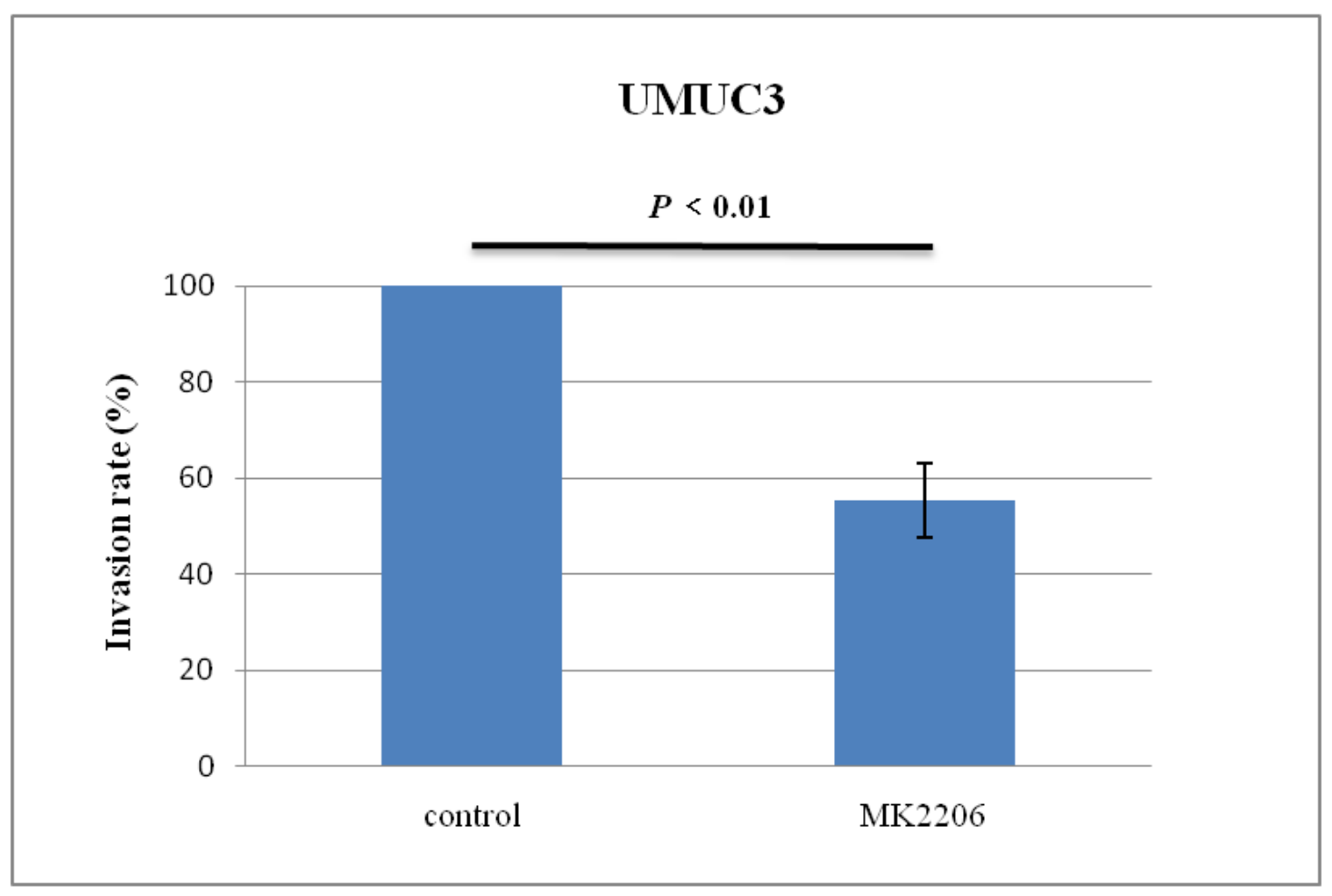


Fig-2E

control

MK2206

Snail

Slug

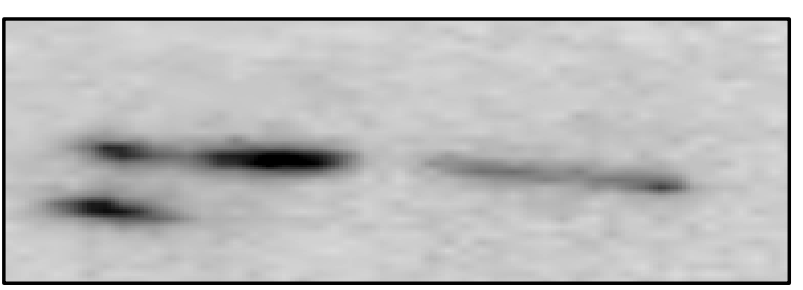

ZEB1

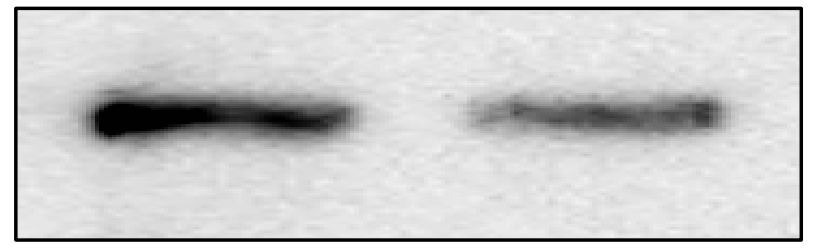

$\beta$-actin
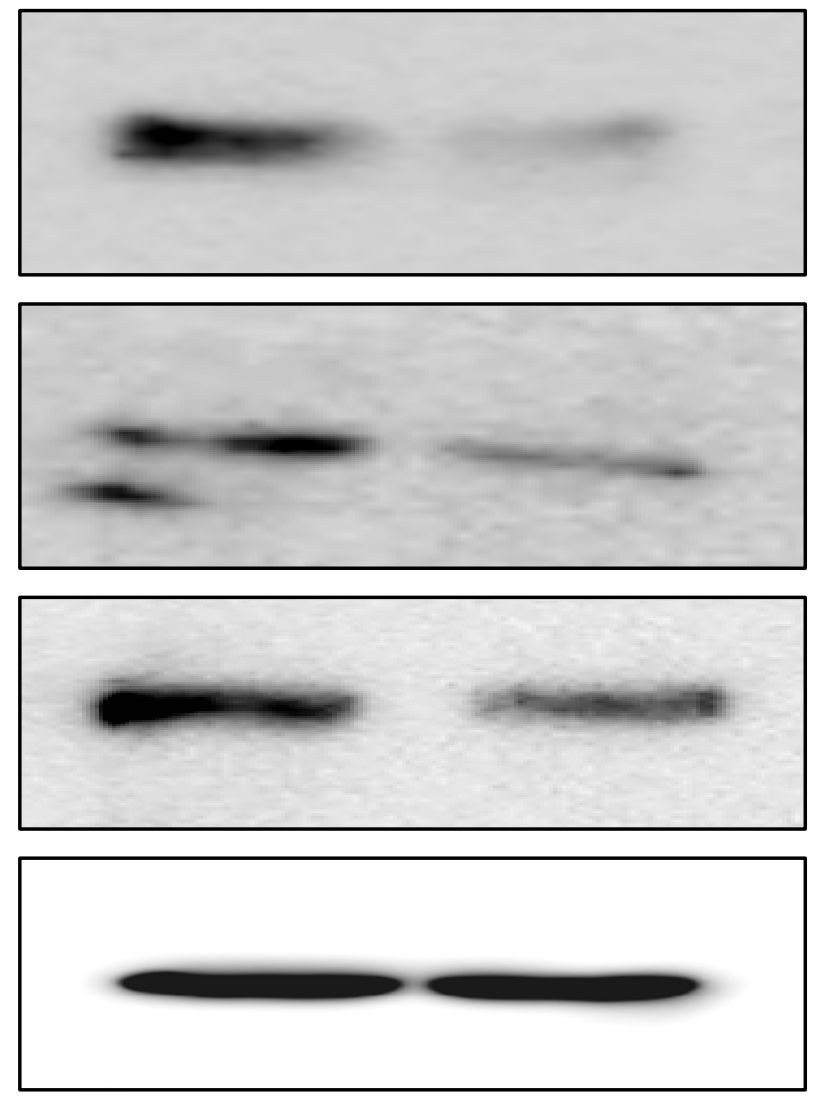
Fig-3A

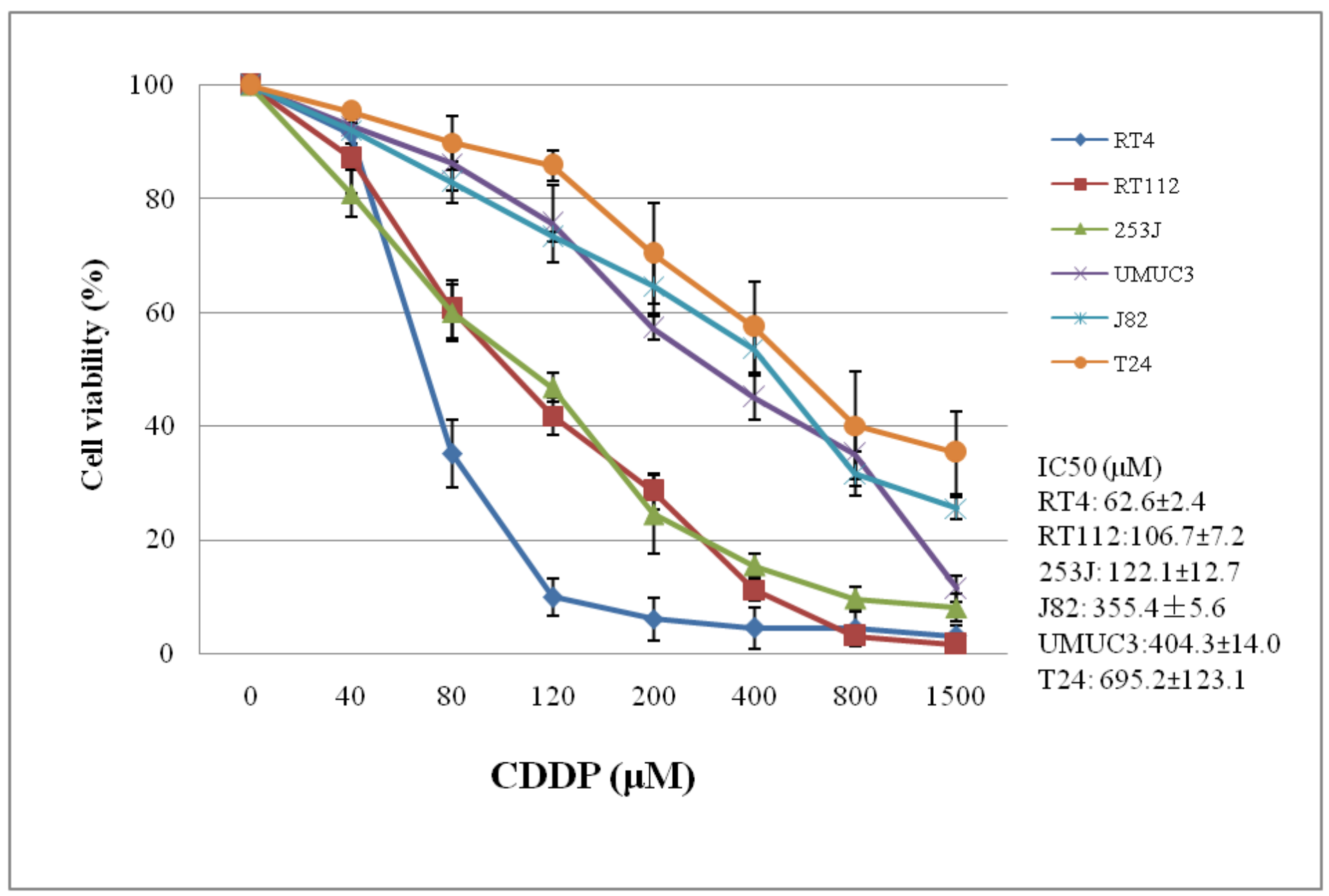


Fig-3B
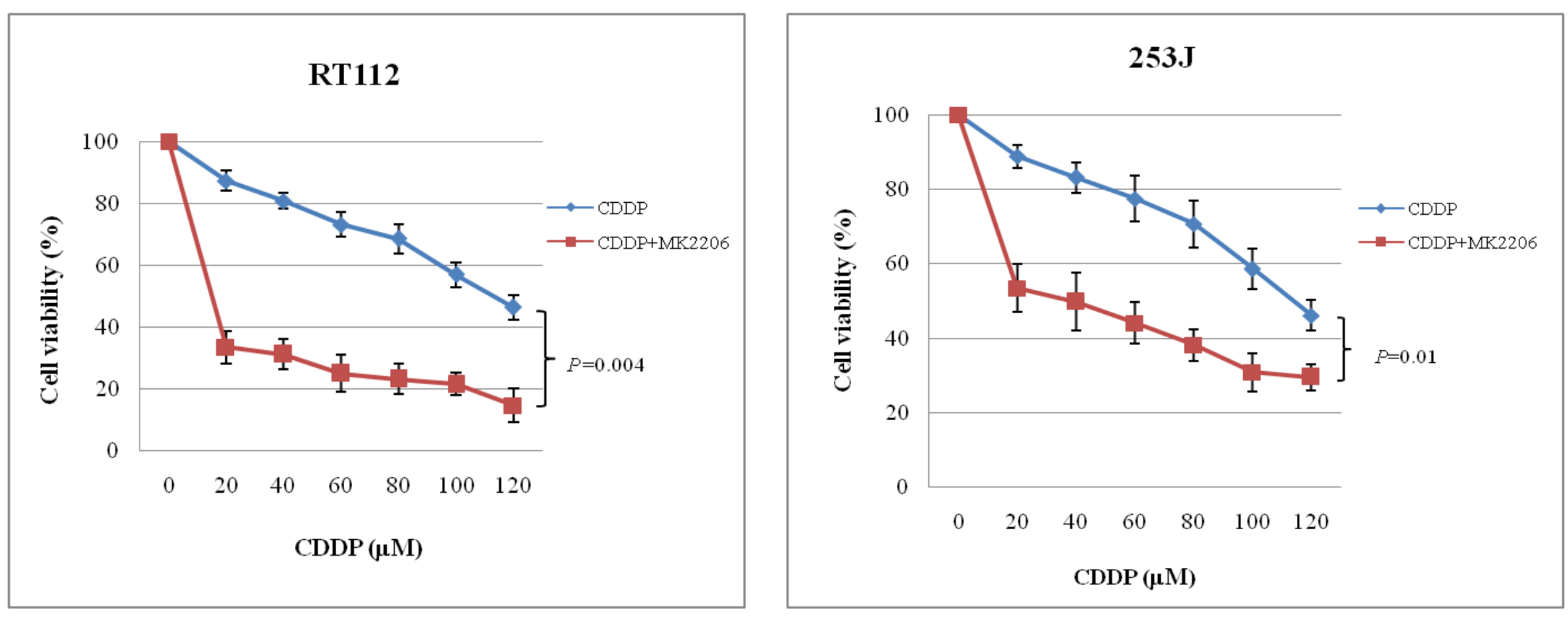
Fig-3B
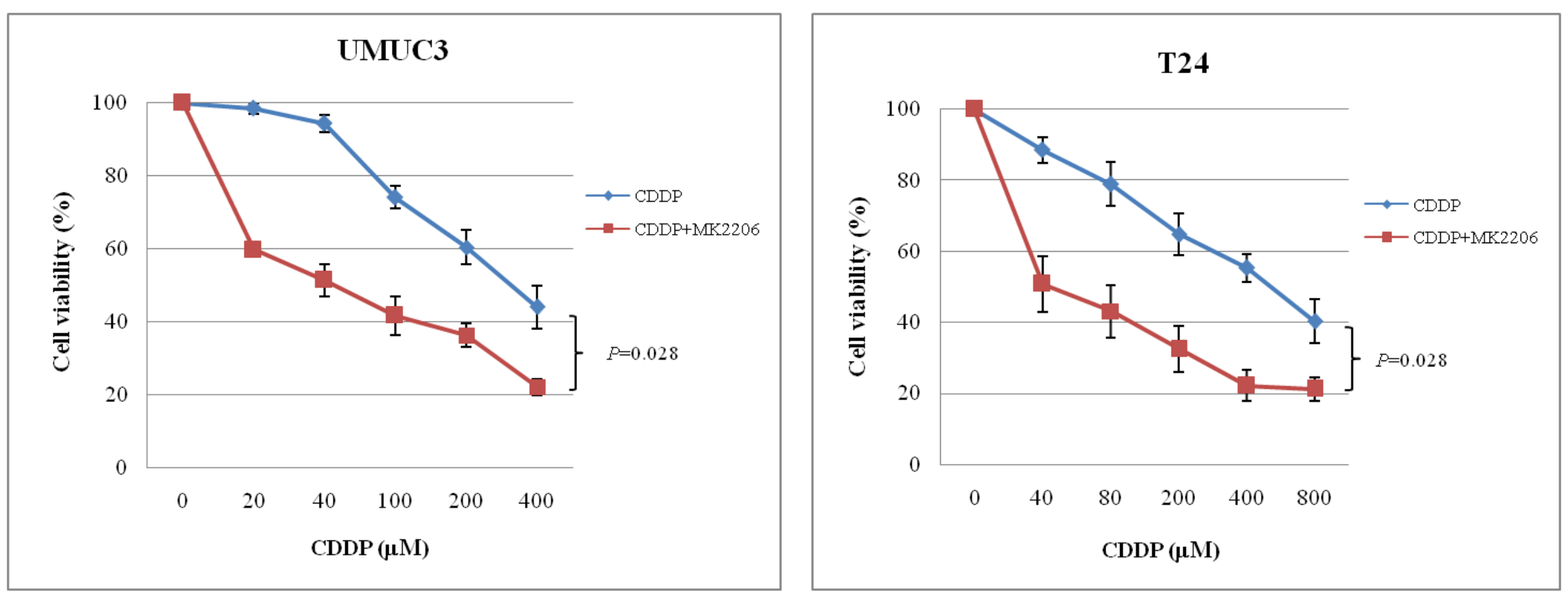
Fig-4A.1

T24

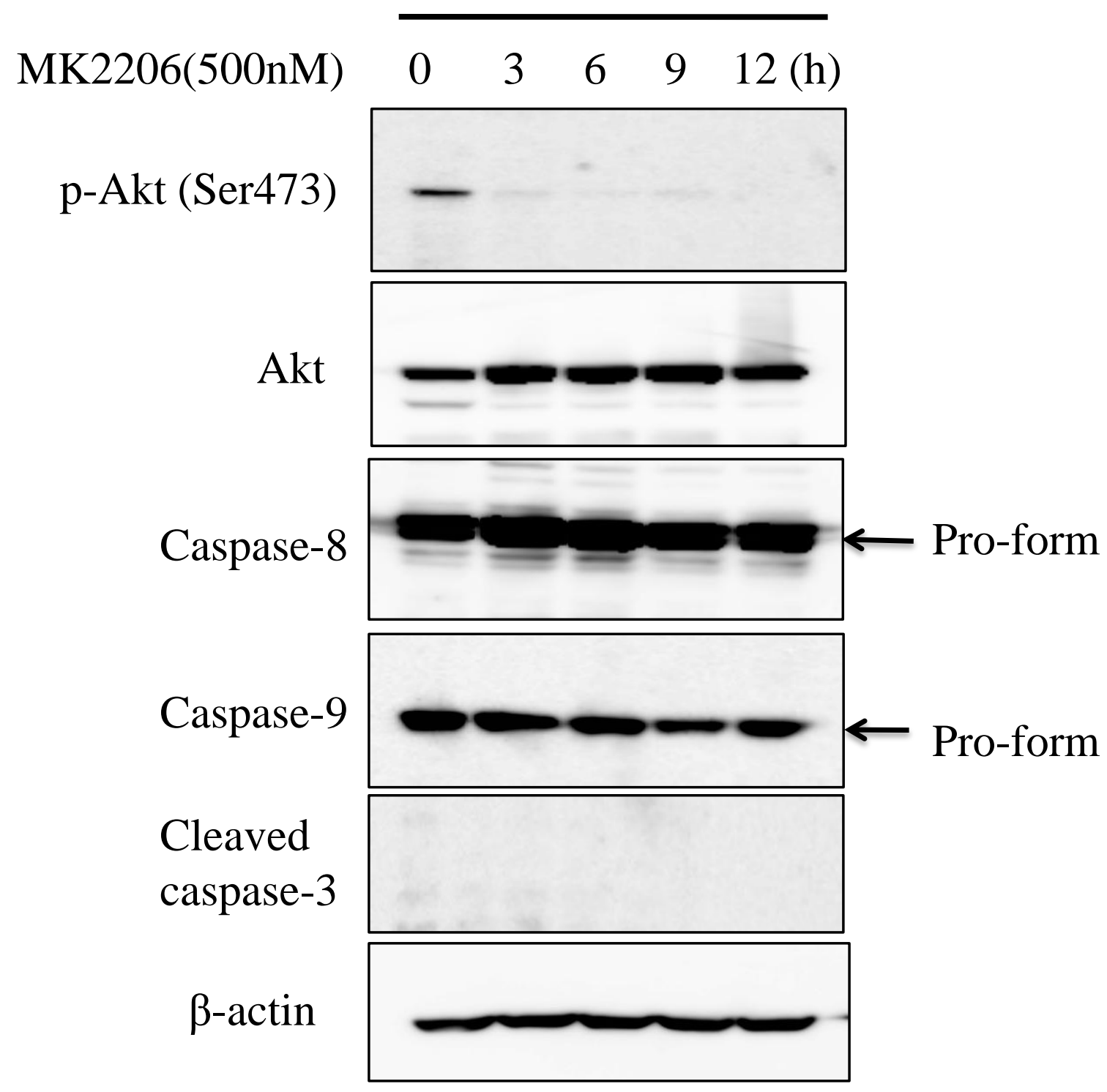


Fig-4A.2

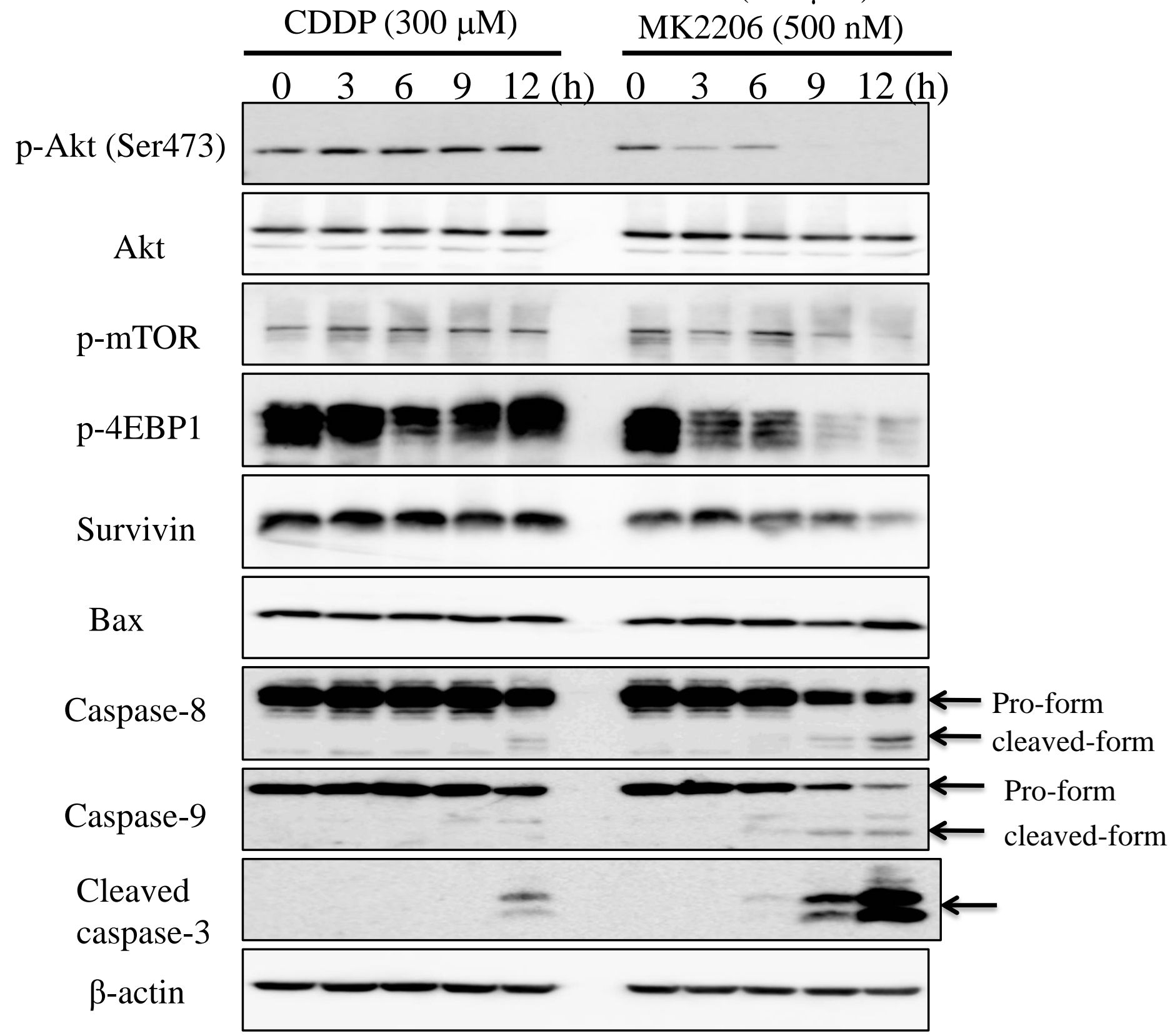




\section{Fig-4B}

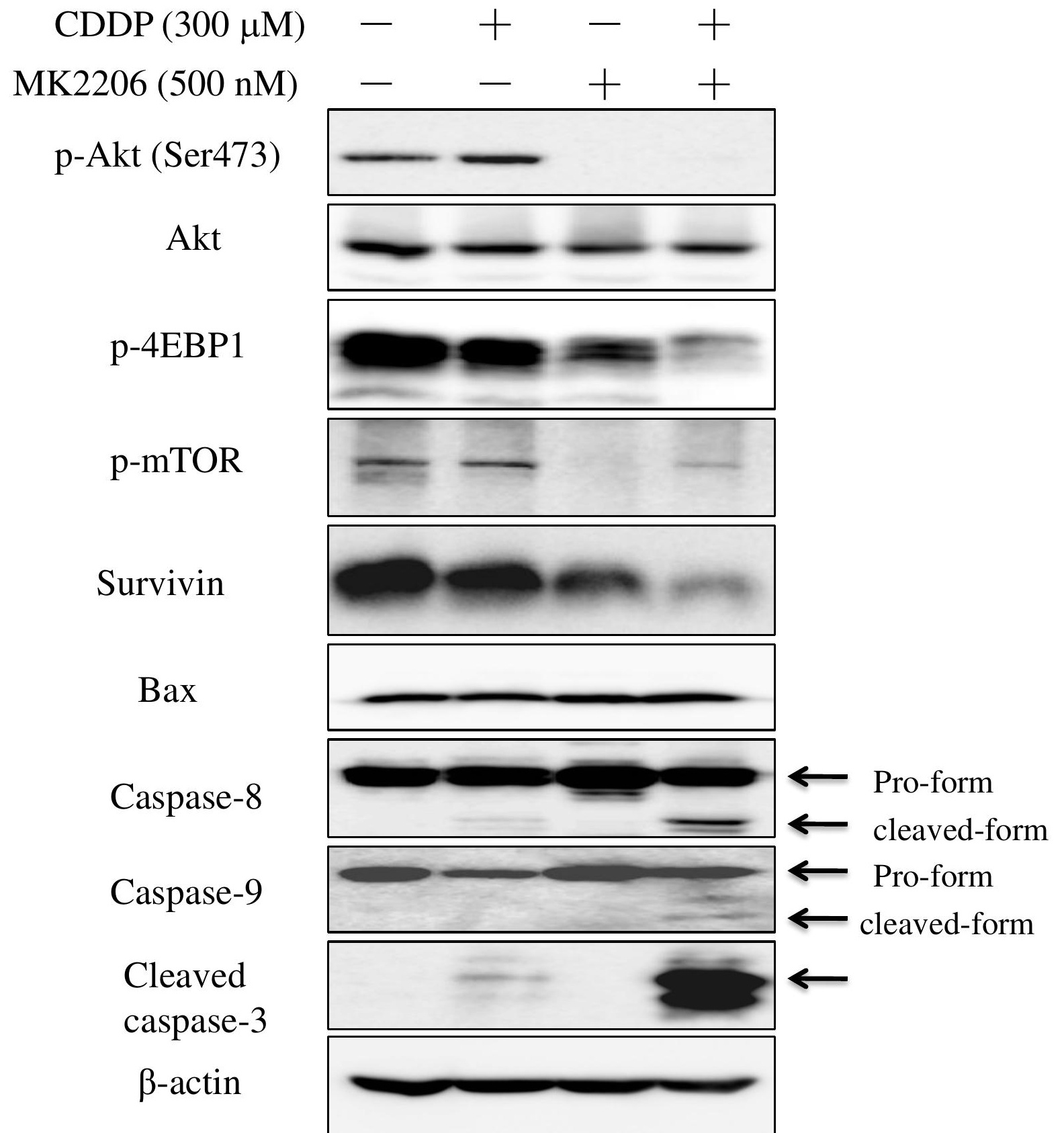


Fig-4C

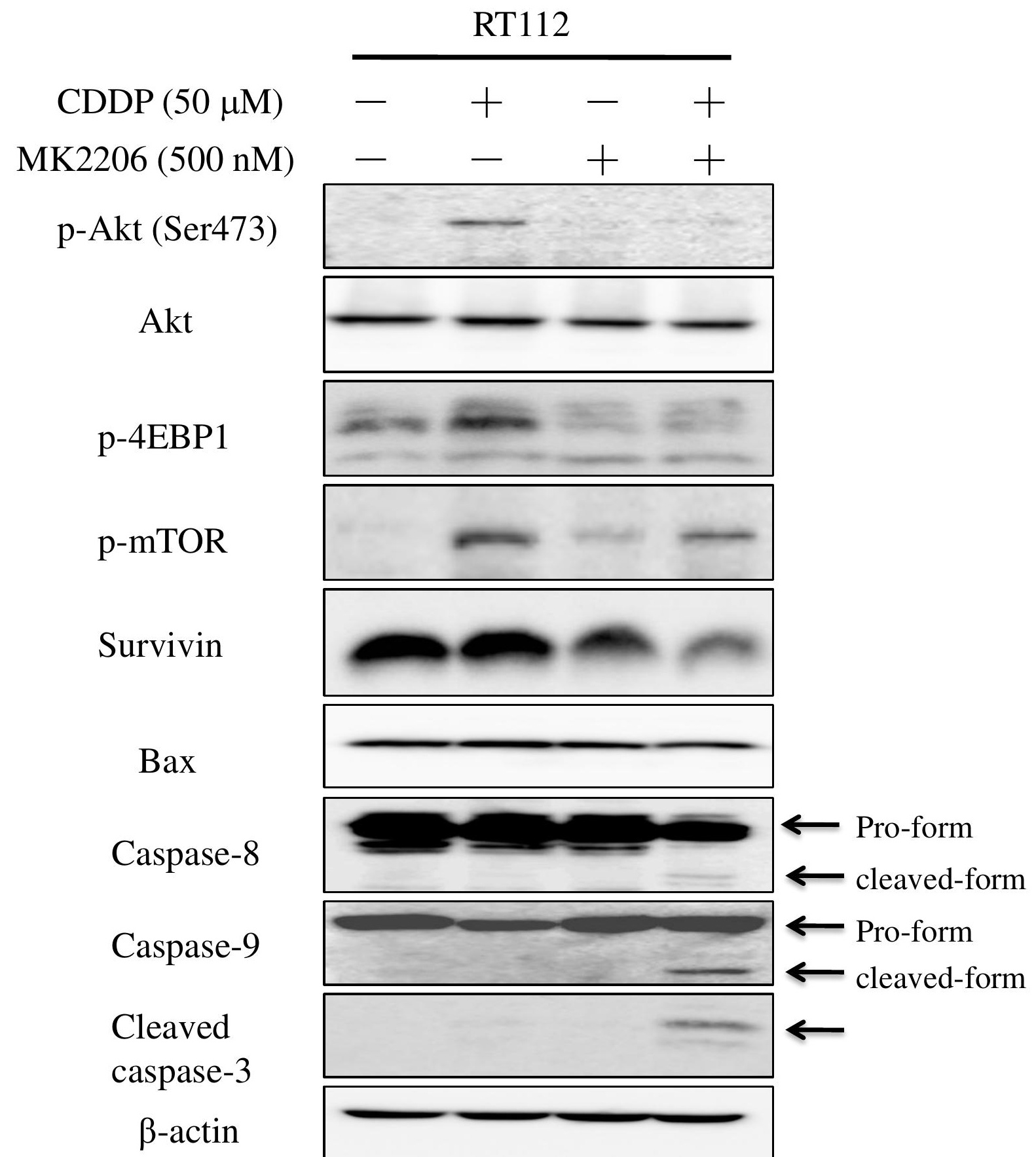




\section{Fig-5A}

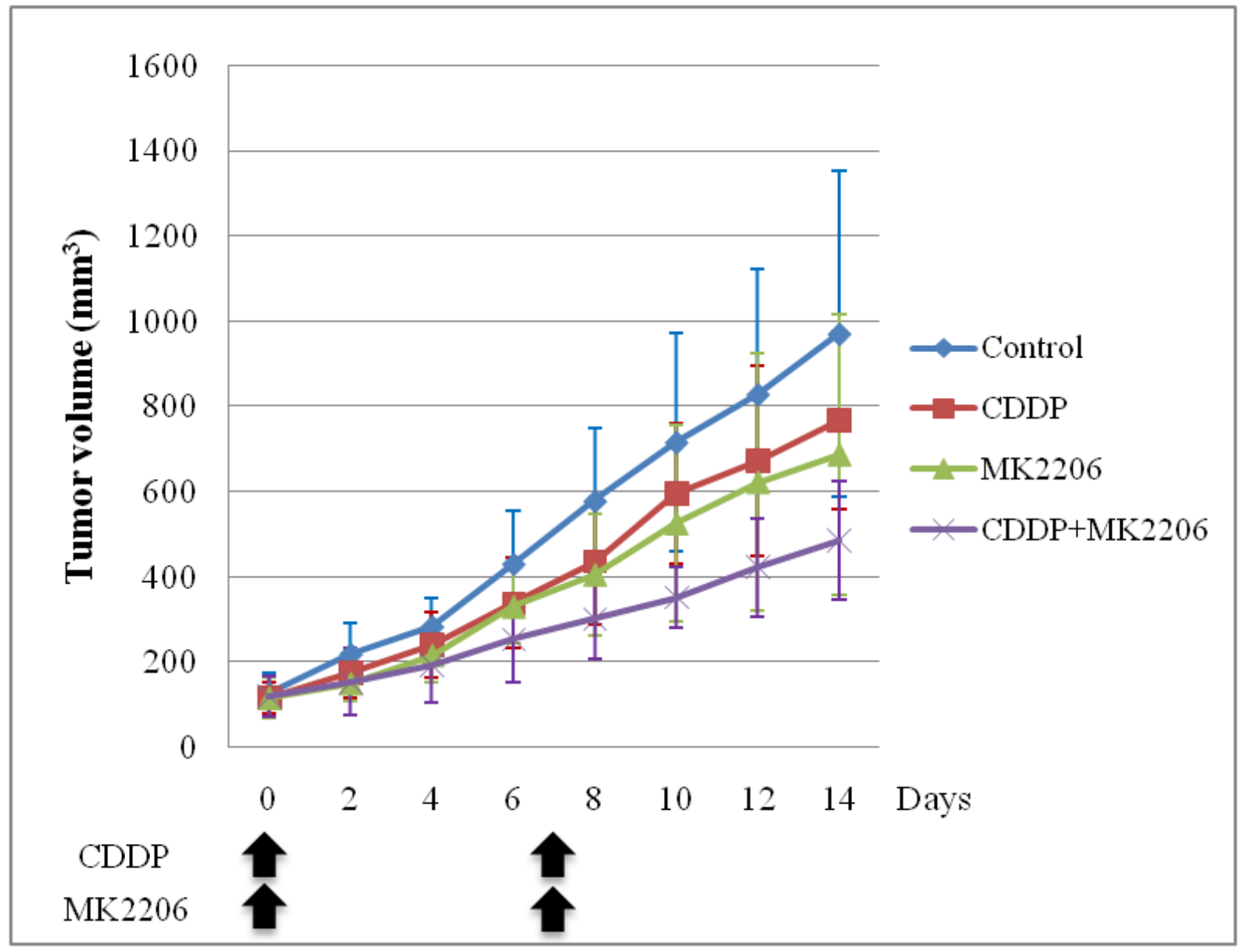




\section{Fig-5B}
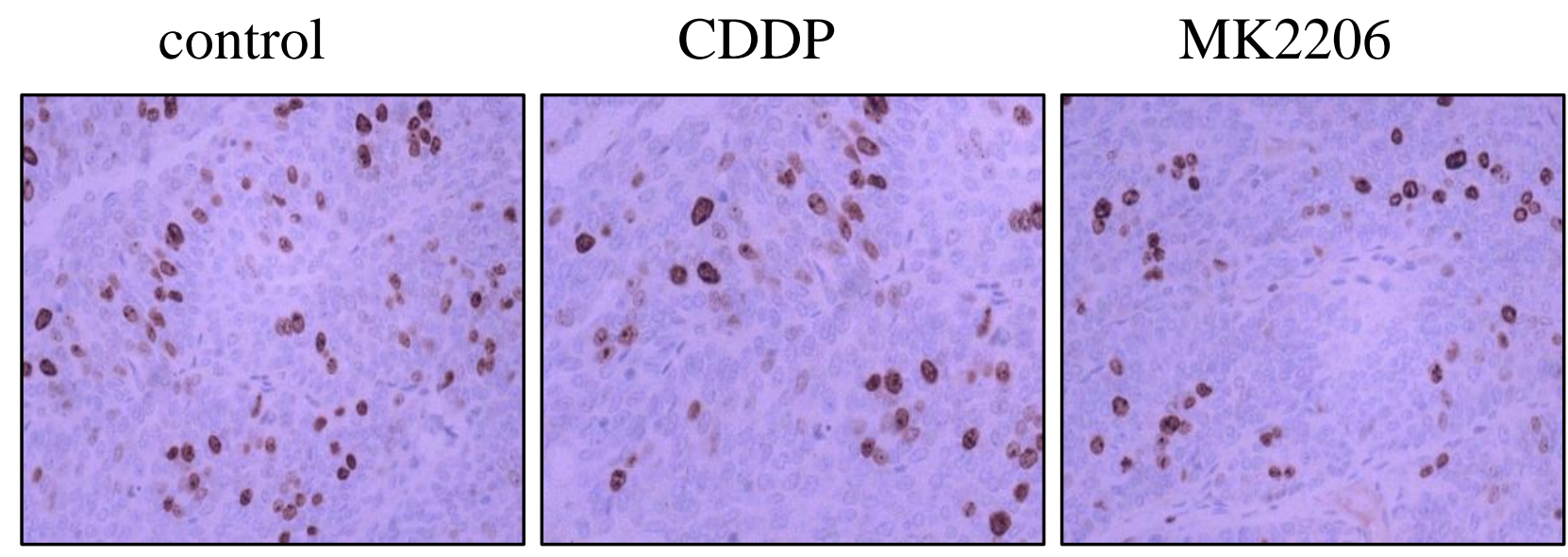

\section{CDDP+MK2206}
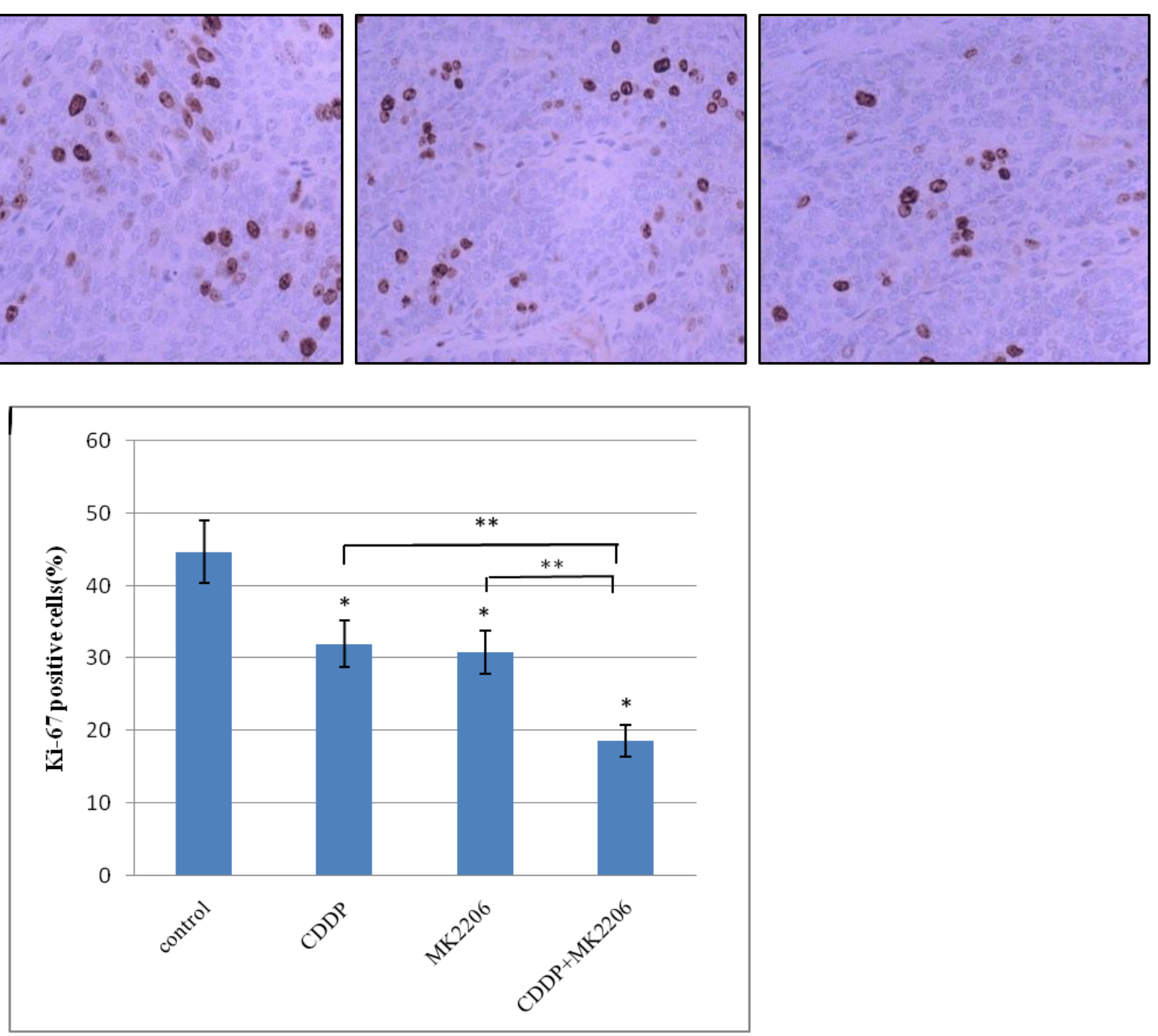